\title{
SUSTAINABLE DEVELOPMENT FROM THE PERSPECTIVE OF THE HERITAGE MANAGEMENT OF THE SARATA MONTEORU TOURIST RESORT
}

\author{
Marcela Antoaneta NICULESCU ${ }^{a}$, Svetlana PLATAGEA GOMBOS ${ }^{b}$, Valentin LAZ $\breve{A R}{ }^{c}$, \\ Ovidiu Andrei Cristian BUZOIANU \\ ${ }^{a}$ INCD EcoIND, Romania \\ ${ }^{b, c, d}$ Bucharest University of Economic Studies, Romania
}

\begin{abstract}
Sustainable development adds to the forefront a new set of values that will have a future model of economic and social progress, values that can present more man and present and future sales needs, the natural environment- protecting and conserving the country, and mitigating damage ecosystems. The present article aims to identify the main strategies meant to be implemented for the sustainable growth of tourism in the studied region, based on the natural heritage. While promoting a leadership of global responsibility, sustainable development management ultimately leads to the change of organizational culture in the sense of acceptance, the level of all layers of an enterprise, the passage and final appreciation of performance through the filter of sustainability. to our sage it represents a dexterous action of necessity.
\end{abstract}

KEYWORDS: management, environment, sustainable development, tourism

\section{INTRODUCTION}

In the last 50 years, tourism has become one of the most important industries in continuous development. However, tourism has also become a major cultural and environmental issue in many areas due to strong short-term development that does not take into account the long-term changes it produces. The concepts put together make up a sustainable tourism strategy have been designed and tested precisely to avoid deteriorating the balance of areas where tourism activities take place and are suitable to be applied in Romania. For many years, Romania was kept somewhat separate from the international tourism system for political reasons (Bran, 1998). Now, with the help of sustainable tourism strategies, Romania can start to benefit from tourism while avoiding the mistakes that have been made in other areas.

To be successful, a balanced approach is needed that focuses on cultural and natural values, it needs the support of local and central authoriti. In this context, it is not the time for disputes or rivalries, good ideas and correct management are needed (Loulanski, 2006).

Sărata-Monteoru (also called Monteoru for short) is a village in Merei commune, Buzău county. Sărata-Monteoru is a spa resort located in the central-western area of Buzău County, about $20 \mathrm{~km}$ northwest of Buzău. The locality belongs administratively to the commune of Merei and was first known among the locals for the healing waters of the salt springs.

The locality is placed in an intracoline depression drained by the Sărata river, at the south-eastern extremity of the Curburii Subcarpathians, between the Istriței Hills, hills covered by a rich vegetation and sheltered from winds. The climate of the depression is continental, with hot and sunny summers, without drafts and precipitation and fog are reduced.

\footnotetext{
* Corresponding author. E-mail address: marcela_mitrita@yahoo.com
} 
The town is also known for its Monteoru culture, an archeological culture dating from the Bronze Age, represented by a large settlement near the eastern edge of today's village, on the Cetăţuia hill.

\section{TOURIST TRAFFIC ANALYSIS}

\subsection{Number of tourists accommodated in tourist pensions}

Tourism indicators provide in a synthetic, mathematical expression, information on various aspects of tourism, beneficial information for measuring the phenomenon and its effects, for anticipating evolutionary trends and last but not least for substantiating development policy in the field (Ioncica, 2004).

The tourist circulation represents the synthesis that reflects the attractiveness and the level of capitalization of the tourist potential; represents the dynamic element, responsible for the increase and diversification of the accommodation base, for the size and modernization of the treatment base and for the intensification of the leisure base (Bole, 2013) The formation of tourist flows depends on a multitude of factors: standard of living (disposable income, budget allocated for vacation), travel possibilities (time available for vacation, time available for travel, distance traveled, means of transportation, vacation splitting, etc.) (Sugandini, 2019).

\subsubsection{Number of arrivals}

The number of arrivals corresponds to the number of tourists, both for Romanian and foreign tourists, who stay in tourist accommodation units (hotels and other accommodation units), in the period considered, respectively 2019.

The tourist arrivals in Sarata Monteoru resort in the analyzed period had a slight growth trend, so in 2019 the most arrivals for tourist purposes were registered in the reception units with a value of 13,071, and in 2013 a number arrived.

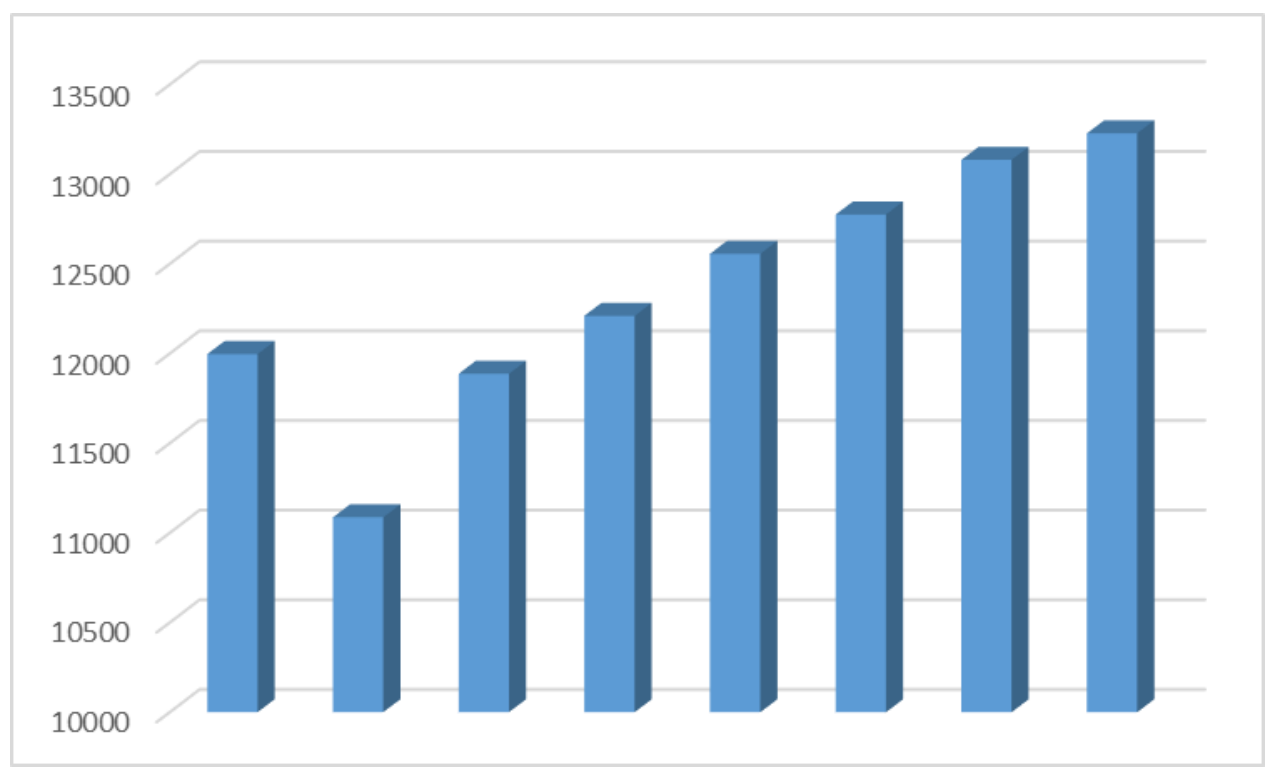

Figure 1. Evolution of the number of arrivals in the period 2012-2019

Source: www.insse.ro

\subsubsection{Number of nights}

The number of overnight stays as shown by the analysis of statistical data has a growing trend, so in 2012 when 64,839 were registered compared to 2019 when 78,084 were registered. 
Table 1. The evolution of the number of overnight stays in the period 2006-2013

\begin{tabular}{|ccccccccc|}
\hline Year & 2012 & 2013 & 2014 & 2015 & 2016 & 2017 & 2018 & 2019 \\
$\begin{array}{c}\text { Total } \\
\text { overnights }\end{array}$ & 64839 & 71577 & 71435 & 73608 & 64986 & 79377 & 76070 & 78084 \\
\hline
\end{tabular}

Source: www.insse.ro

\subsubsection{Average length of stay}

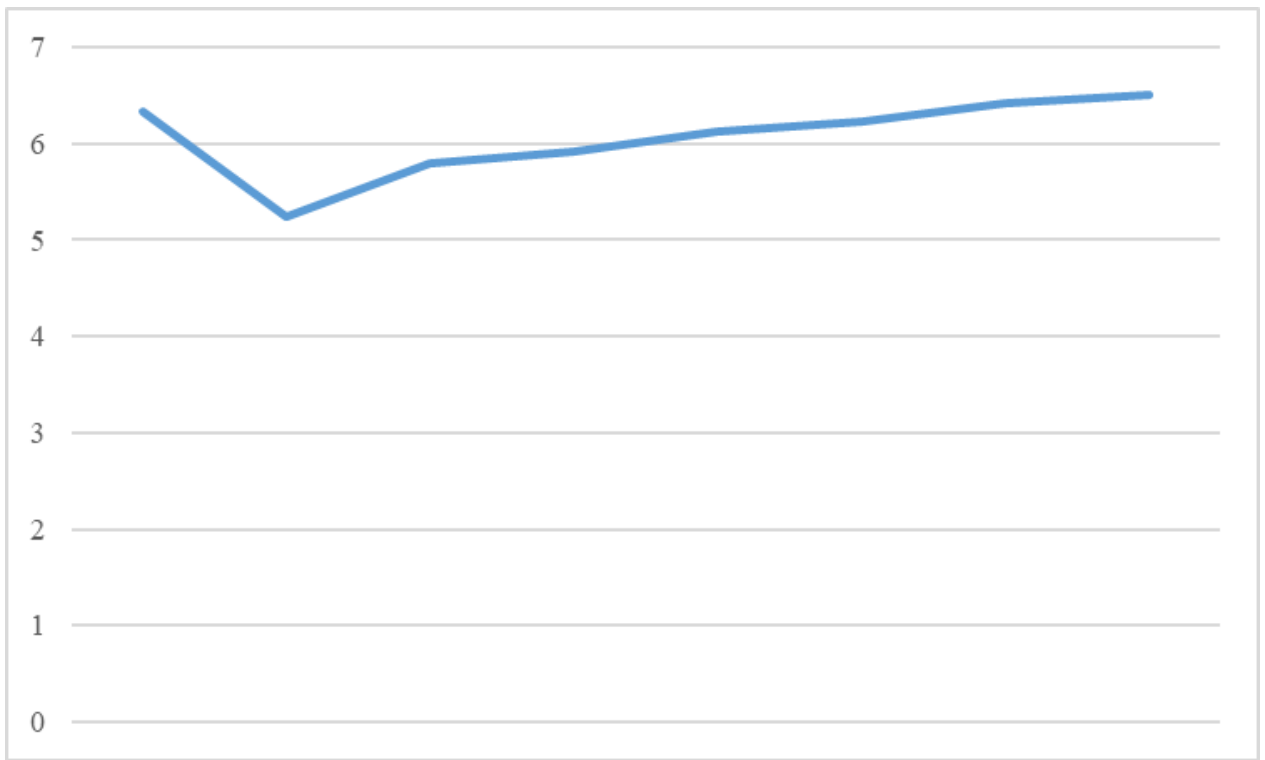

Figure 2. The evolution of the average length of stay in the period 2012-2019

Source: www.insse.ro

The analysis of statistical data shows that the average length of stay in Sărata Monteoru resort decreased from 6.39 days in 2012 to 5.7 days in 2019. This is due to domestic economic conditions and the orientation of tourists to other tourist destinations.

\section{STRATEGIC APPROACHES FOR SUSTAINABLE DEVELOPMENT}

It is estimated that the long duration of elaboration and adoption of appropriate legislation, lack of financial resources for modernization and development of resorts, lack of advantageous conditions for granting (Bandarin, 2015) loans for tourism development, decreased purchasing power, but also the management of Romanian spas, in many cases inadequate, were the main causes of the state of degradation and crisis that affected this form of tourism. The situation would have evolved better if the decision-makers at the level of local councils and the management of the companies had set their objectives well and chosen appropriate strategies:

The main strategic objectives of these resorts could be:

- Increasing the competitiveness of its own spa offer;

- Strengthening the position on the internal and external market.

\subsection{Strategy for redevelopment and re-equipment of treatment centers in existing sanatoriums}

This strategy will focus on modernizing the treatment bases, both by equipping with modern medical equipment for classic treatment, and by creating fitness, anti-stress, or beauty centers, specific to health tourism. Capitalizing on the chance that this new concept, which means the 
transition from the medicine of the sick man to the medicine of the healthy man, gives to the spa tourism is the key to the relaunch of this form of tourism (Kalman, 2014).

The coordinates of such a strategy are:

- the selection, based on a functional zoning, of the spaces in the treatment base that will be the object of modernization and of the spaces that, through redistribution, could be allocated to the welfare tourism services;

- rearrangement of the spaces with the destination of spa treatment, which in most cases registers an advanced degree of wear;

- the purchase of modern equipment, the existing one being physically and morally outdated;

- selection and training of the staff that will provide assistance for the new services that will be offered;

- performing an economic analysis, establishing the estimated costs for modernization and the amount that can be covered from own sources;

- elaboration of a feasibility study in order to obtain the credits necessary for the realization of the program.

\subsection{Strategy for modernization of accommodation, food, leisure equipment and development of the service offer}

Given that the vast majority of tourist reception and catering facilities were built before 1989, being designed for mass tourism, and little investment has been made in the last 15 years, it is imperative to implement modernization programs and raising the comfort level. Despite the significant investment effort, these programs need to be implemented in order to be competitive in the similar European market.

One of the big problems of the offer of the spa resorts is also the leisure. Far from the demands of demand and what is offered in spas in countries with a tradition of the European Union, the leisure in our resorts must be reformulated "by:

- creation and endowment of club premises within the hotels;

- construction, where conditions allow, of leisure complexes with projection and performance halls, sauna, massage, fitness, bowling, table tennis, swimming pool and small food units (confectionery, pizza, café-bar);

- rearrangement and modernization of the old agreement facilities: fun games, mechanical and electronic games, etc.

- in the vicinity of nationally known spas, at a reasonable distance from an airport with international traffic, there are special locations for the establishment of golf courses, which in time would become points of attraction for amateur or professional foreign tourists, with significant economic advantages for the respective areas;

- located in hilly or mountainous areas, where the design of riding programs in collaboration with horse owners would not present great difficulties and would be effective, this form of leisure can be attractive for tourists coming to rest and recovery.

The services related to each structure will have to be prepared with maximum exigency, and the personnel hired to offer these services will have to show, besides the adequate qualification, kindness and interest in satisfying the exigencies of the clients.

\subsection{Differentiation strategy}

Compared to the offers of the competing countries, the Romanian spa tourism cannot miss the chance to make the most of the therapeutic mineral substances that have a unique character by applying the differentiation strategy (Aas, 2005). Among the therapeutic mineral substances that fall 
into this category are the mofetic and sulphatic gases considered rarities of nature and even unique in Europe in the case of sulphates. The high therapeutic value of mofetic gases determined by extensive specialized research, as well as the favorable curative valences of sulfates make them to be considered specific elements of great interest of Romanian balneology.

Continuing an aggressive promotion of the originality of the product made by capitalizing on skunks and scientific events such as the one mentioned, supported by strategies to modernize the treatment, accommodation, food and leisure base, with a good price strategy (flat rate but also high price), can make Sărata Monteoru a point of reference in Buzoian, national and why not European spa tourism.

The change in the structure of demand, generated by the development of welfare tourism, requires the choice of diversification strategy in order to meet the requirements of as many segments of tourists as possible. This type of strategy is the key to success in the path that each resort aims to take to come to market with a competitive offer, comparable to that of European Union countries. In the current conditions of the global society, determined by the Covid-19 pandemic, coherent strategies are needed to relaunch this form of niche tourism. In this sense, it is necessary to relocate the natural resources in order to access them, for an adequate management.

It is a diversification that must respond to the travel motivations of healthy people, young and old, who choose wellness or primary prophylactic treatment to maintain and improve their health, to maintain the appearance of their body and prepare the body to withstand stress and polluted environment (Stanciulescu, 2020).

The current industrial civilization has generated a series of diseases such as:

- hypokinetic syndrome, determined by sedentary lifestyle and lack of demand for physical effort in professional activity, transport and life at home (TV, computer, etc.);

- the syndrome of maladaptation, of deconditioning, with the reduction of the thermoregulation functions, in the conditions of nature rupture, of exposure to thermal factors;

- toxic effects of polluted air and smoking;

- unbalanced and unhygienic diet, with excessive consumption of animal fats, concentrated carbohydrates, irritants to the stomach or toxic to the liver - spices, alcohol, excess coffee, chemicals added to soft drinks or food (dyes, preservatives), the so-called "E" which frequently causes a digestive and metabolic pathology in chronic evolution.

The prevention of these groups of diseases can be done very successfully in spas, which in addition to aerosols have either mineral water that can be consumed preventively in digestive rest or diuresis, or other natural healing factors favorable to the prevention of various diseases. diseases. Diversification strategies involve the creation of wellness centers, where the services are of the best quality and provided by true professionals.

Also, in the application of diversification strategies, it will be taken into account that the new products offered include a minimum of various types of cure. Comfort treatment (mise en forme) which through climate therapy, physiotherapy, hydrotherapy, diet therapy and psychotherapy can combat hypokinetic syndrome, balances the nervous system, trains thermoregulatory functions and balanced diet.

Apart from the sparing climate specific to the resorts proposed in this group, the anti-stress treatment methodology relies on the relaxing, sedative effects of balneotherapy and hydrotherapy procedures, combined with sedative electrotherapy techniques with electromagnetic fields, massage, physical therapy, psychotherapy and an appropriate diet, in programs with an optimal ratio between activity and rest, with sufficient hours of sleep.

For the spas located in the first places of the presented hierarchy, the necessary conditions for performing the anti-stress cure can be successfully achieved.

For those with certain risk factors, young people and adults, or working in environmental conditions and in demanding activities, "health cures" will be provided to prevent certain pathologies such as 
health care for subjects with a predisposition to degenerative rheumatic diseases in the resort Sărata Monteoru.

The strategy for the development of specifically Romanian products is a way to relaunch the Romanian spa tourist product on the international market. "Gerovital" products for the treatment of rheumatic, nervous and anti-aging diseases, "Aslavital", for the treatment of nervous and anti-aging diseases, "Boicil", for rheumatic diseases and arterial disorders are recognized and appreciated abroad.

Efforts to attract demand through the strategies presented need to support the new image. It is necessary to edit a brochure, make an advertising CD-ROM and a website for each resort. It is also necessary to promote the resort and the area on foreign markets, with the spa offer and other local tourist attractions, both at specialized fairs and in the foreign press.

\section{CONCLUSION}

The development of spa tourism is the essential condition for well-being and better quality of life. Our country has many natural riches, but they are not valued enough to give value to this country. In the future, a tourism of leisure, order and leisure will be required, which through the arrangements made will be a source of regeneration for the year bothered by the aggressions of urban life (congestion, noise, etc.) and the rhythms of intensive activity.

In the future, spa tourism will flourish again if it is invested and people will choose a place for vacation and relaxation at the same time where it can treat almost any kind of illness. Spa tourism must be invigorated, it must correspond to international standards, it is a natural wealth not properly valued, a factor that can contribute to the recovery of trade balance.

An overly strong orientation towards the commercial part of the development of spa tourism to the detriment of the ecological one will certainly lead in time to a degradation of the area, diminishing its commercial value.

The development of tourism has as fundamental premise the protection and conservation of the tourist potential, the prevention of its degradation, this being the problem of maximum importance and topicality, which must be an integral and inseparable part of the general policy of tourism development.

The consistent application of a policy of protection of the tourist potential is urgent and necessary because, continuously, new and serious damages of the tourist resources appear, some already produced, not being able to be remedied, but most of the times, it had proved its usefulness and efficiency over time, their beneficiaries being future generations.

The measures imposed on the protection of the tourist potential and the prevention of its degradation follow, mainly: the scientific and rational capitalization of the tourist resources, the sensitization of the economic units whose polluting activity affects the tourist potential.

territorially or on more restricted territories, so that their tourist capitalization is solved in the context of the capitalization of all natural resources and environmental protection.

\section{AKNOLEDGEMENTS}

We thank the work team for the help offered in making this article. I wish to thank the National Institute of Statistics for his assistance with the statistics used in this report. I would like to express my deep gratitude to my coleagues for their patient guidance, enthusiastic encouragement and useful critiques of this research work.

This work was cofinanced from the European Social Fund through Operational Programme Human Capital 2014-2020, project number POCU/380/6/13/125015 "Development of entrepreneurial skills for doctoral students and postdoctoral researchers in the field of economic sciences." 


\section{REFERENCES}

Aas, C., Ladkin, A., \& Fletcher, J. (2005). Stakeholder collaboration and heritage management. Annals of Tourism Research, 32(1): 28-48.

Bandarin, F. \& Van Oers, R. (2015). Reconnecting the City: The Historic Urban Landscape Approach and the Future of Urban Heritage, Wiley-Blackwell, Chichester.

Bole, D., Pipan, P., \& Komac, B. (2013). Cultural values and sustainable rural development: A brief introduction, Acta Geographica Slovenica 53-2. Ljubljana, Slovenia.

Bran, F., Marian, D. \& Simon, T. (1998). Economics of tourism and environment, Economic Publishing House, Bucharest.

Ioncica, M., Petrescu, C., Popescu, D. (2004). Strategies for the development of the tertiary sector, Uranus Publishing House.

Kalman, H. (2014). Heritage Planning: Principles and Process, Routledge, Oxan and New York, NY.

Loulanski, T. (2006). Cultural Heritage in Socio-Economic Development: Localand Global Perspectives Environments, 34 (2).

Stanciulescu, G. C., Felicetti, G. (2020). Researching the Intent and Attitude of Local Communities from Protected Areas Regarding the Development of Eco-Sustainable Goods and Services through Ecotourism. The Case of National Park of Sibillini Mountains, uality- Access to Success, Vol. 21, No. 175.

Sugandini, D., Effendi, M., Susilo, P. (2019). Tourism, Quality- Access to Success, Vol. 20, No. 173. 